\title{
OPEN Synthesis and release behavior of layered double hydroxides-carbamazepine composites
}

\begin{abstract}
Ma. F. Peralta ${ }^{1,2,3}$, S. N. Mendieta ${ }^{1 凶}$, I. R. Scolari ${ }^{2,3}$, G. E. Granero ${ }^{2,3}$ \& M. E. Crivello ${ }^{1 \bowtie}$
Carbamazepine (CBZ) was incorporated into layered double hydroxides (LDH) to be used as a controlled drug system in solid tumors. CBZ has a formal charge of zero, so its incorporation in the anionic clay implies a challenge. Aiming to overcome this problem, CBZ was loaded into LDH with sodium cholate (SC), a surfactant with negative charge and, for comparison, without SC by the reconstruction method. Surprisingly, it was found that both resultant nanocomposites had similar CBZ encapsulation efficiency, around 75\%, and the LDH-CBZ system without SC showed a better performance in relation to the release kinetics of CBZ in simulated body fluid ( $\mathrm{pH} \mathrm{7.4)} \mathrm{and} \mathrm{acetate}$ buffer simulating the cellular cytoplasm ( $\mathrm{pH} 4.8$ ) than the system with SC. The CBZ dimensions were measured with Chem3D and, according to the basal spacing obtained from X-ray patterns, it can be arranged in the LDH-CBZ system as a monolayer with the long axis parallel to the LDH layers. Fourier transform infrared spectroscopy and solid state NMR measurements confirmed the presence of the drug, and thermogravimetric analyses showed an enhanced thermal stability for CBZ. These results have interesting implications since they increase the spectrum of LDH application as a controlled drug system to a large number of nonionic drugs, without the addition of other components.
\end{abstract}

Currently, cancer is the second cause of death in the world, which makes it one of the most important subjects of study in modern medicine. From the diverse types of the disease, solid tumors are the most frequent, with breast cancer in the first place (2.26 million cases in 2020), followed by lung (2.21 million cases in 2020), and colon and rectum (1.93 million cases in 2020) ${ }^{1}$. At present, one of the principal treatments against cancer is chemotherapy, which consists in the use of drugs that predominantly kill tumor cells. Even with the advances in the last decades, there is still ample room for improvement since it produces many side effects ${ }^{2,3}$.

Another serious obstacle for effective anticancer drugs is their low solubility in water and low bioavailability; most of them require a vehicle to be carried in the organism. In this sense, many drug administration systems have been developed; among them, polymeric nanoparticles, micelles and liposomes are the most outstanding ${ }^{2,4}$. Inorganic nanosystems, among which are the layered double hydroxides (LDH), are becoming strong competitors ${ }^{5-7}$. LDH are composed of metal cationic layers and interlamellar spaces filled with negative ions or anionic drugs $s^{8-10}$. These substrates have several advantages: defined properties for the controlled release of the drugs (stability and consequent drug protection during blood circulation ( $\mathrm{pH}$ 7.4) and good endosomal escape and biodegradation, with consequent drug release, in the cellular cytoplasm ( $\mathrm{pH}$ between 4 and 6) ${ }^{11-13}$ ), biocompatibility, efficient penetration of the cellular membrane ${ }^{14,15}$ and protective effect for the drug against temperature, light, humidity and oxidation ${ }^{16,17}$. Additionally, LDH have the advantage of being nano-sized, from 20 to $200 \mathrm{~nm}$, which is a fundamental property for drug delivery systems intended for systemic administration.

Remarkably, there is not a commercial medication that uses LDH as a vehicle of the active principles yet. However, the necessity of new systems and the benefits of these carriers are indisputable, which leads to an urgent need to advance in the research of these inorganic nanosystems. Only the empty LDH, of the hydrotalcite type, is currently commercially available and it is used as antacid for the treatment of stomach diseases ${ }^{18}$.

\footnotetext{
${ }^{1}$ Centro de Investigación y Tecnología Química - CONICET - Universidad Tecnológica Nacional, Regional Córdoba, Maestro López Esq. Cruz Roja Argentina, S/N, X5016ZAA, Córdoba, Argentina. 'Unidad de Investigación y Desarrollo en Tecnología Farmacéutica - CONICET - Universidad Nacional de Córdoba, Córdoba, Argentina. ${ }^{3}$ Departamento de Ciencias Farmacéuticas, Universidad Nacional de Córdoba, Córdoba, Argentina. ${ }^{\square}$ email: smendieta@frc.utn.edu.ar; mcrivello@frc.utn.edu.ar
} 


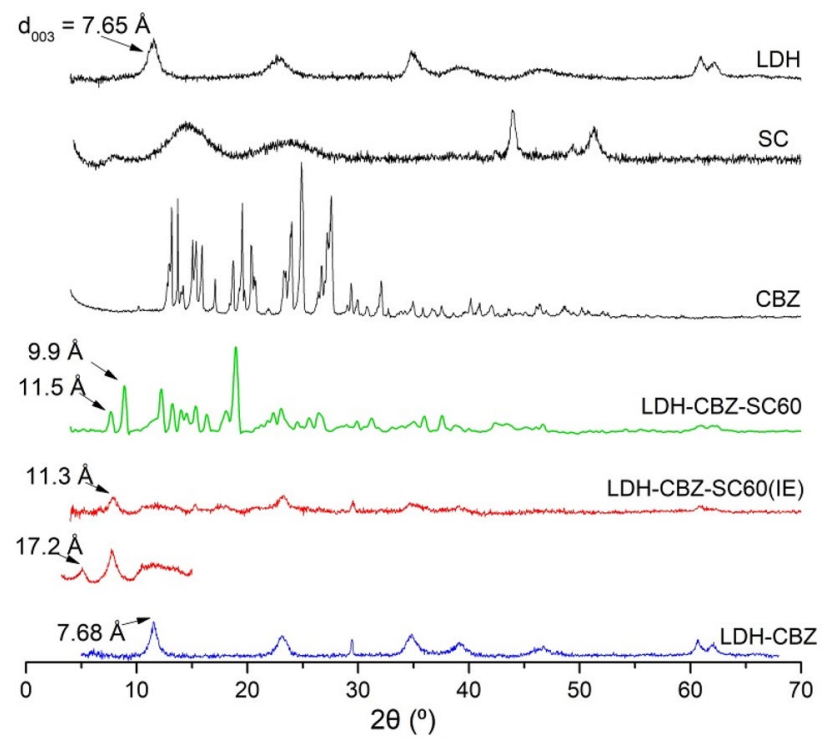

Figure 1. Powder X-ray diffraction patterns of LDH, CBZ, SC, and composites.

Another challenge for modern medicine in the field of chemotherapy is to find novel anticancer drugs. With this objective, approved drugs against other kinds of diseases are being tested in different tumors. To date, the drugs studied in LDH are methotrexate, cisplatine, 5-fluorouracil and doxorubicin ${ }^{19-21}$. However, anticancer drugs without anionic charges or new molecules with potential anticancer activity have not been tested. This is important for the success in the search for new anticancer treatments, especially because the use of LDH can improve the antitumor activity of the new molecules ${ }^{19,20,22,23}$. Carbamazepine (CBZ) is an anticonvulsant drug with a formal charge of zero. It has shown efficacy against some solid cancer cell lines, such as human breast cancer ${ }^{24,25}$ and human colon adenocarcinoma ${ }^{26}$. However, CBZ also produces alterations in red blood cells ${ }^{27}$.

$\mathrm{CBZ}$ is poorly soluble in water, and many authors have increased the solubility through its complexation with D-gluconolactone ${ }^{28}$, polymers ${ }^{29}$, cyclodextrins ${ }^{30}$ or surfactants such as sodium lauryl sulfate and Tween $80^{31}$. Few works studied the incorporation of $\mathrm{CBZ}$ in different matrices for water remediation; this includes adsorption of CBZ on silica-based porous materials ${ }^{32}$, on granular carbon nanotubes /alumina hybrid adsorbent $\mathrm{t}^{33}$, and on hematite nanoparticles ${ }^{34}$. To the best of our knowledge, no studies have been performed with CBZ incorporated in $\mathrm{LDH}$, and no systems have been designed to increase CBZ anticancer activity. The incorporation of CBZ in an LDH system can increase its activity since these nanoclays are excellent intracellular delivery carriers ${ }^{18}$. The internalization of $\mathrm{LDH}$ into the cells can be mediated mainly via clathrin endocytosis when the nanoparticles range between 50 and $200 \mathrm{~nm}$ in diameter ${ }^{35-38}$. This endocytosis is enhanced by the positive surface charges of the nanoclay. Once in the cytoplasm of the cells, the composites are released from the endosomes, the LDH degrade due to the acidic $\mathrm{pH}$ and the drug can quickly produce its anticancer effect. Moreover, LDH are biodegradable, which implies that they are rapidly eliminated from the body without leaving traces in other organs ${ }^{8}$. Finally, these substrates have very low toxicity, especially when compared to silica, carbon nanotubes and iron oxides; LDH with a size of 100-200 nm produce less inflammation, membrane damage, and cell proliferation ${ }^{8}$.

Sodium cholate (SC) is a bile salt surfactant with negative charge that forms micelles at the critical micelle concentration. In the process, the drugs that are in the medium can be encapsulated into the micelles. SC can be used to either enhance the solubility of drugs by offering a hydrophilic and a hydrophobic face ${ }^{39}$ or give negative charge $e^{40,41}$.

In this work, we propose the use of a drug with potential anticancer activity that is not currently used as cytotoxic, with the increase of its activity and its selectivity by incorporating it in an inorganic solid, taking advantage of the LDH capability to avoid drug action during circulation and enhanced tumor cell penetration by clathrin endocytosis. As most of these drugs have no formal charge, a functionalization of the molecule could be needed for their incorporation in the substrate. In this way, CBZ was incorporated into LDH composed of $\mathrm{Mg}-\mathrm{Al}-\mathrm{NO}_{3}$ with $\mathrm{SC}$ by using two methods: ionic exchange and reconstruction. The reconstruction method was also performed by loading the CBZ without SC in order to study a possible incorporation of the drug into $\mathrm{LDH}$ through weak interactions. Different techniques were applied to characterize the systems and to determine their efficacy as drug carriers.

\section{Results}

The XRD patterns of simple LDH (solid host) and CBZ intercalated, LDH-CBZ, with or without SC60 (reconstruction and ion exchange method) are shown in Fig. 1. The diffraction patterns of LDH and LDH-CBZ samples show quite sharp $\left(\begin{array}{lll}0 & 0 & l\end{array}\right)$ and $\left(\begin{array}{lll}1 & 1 & l\end{array}\right)$ peaks, typical of a well-crystallized material. The basal spacing $\left(\mathrm{d}_{003}\right)$ corresponding to $\mathrm{NO}_{3}^{-}$ions was $7.65 \AA$; this value was very similar to that of the LDH-CBZ (7.68 $⿱$ A). CBZ dimensions 
A

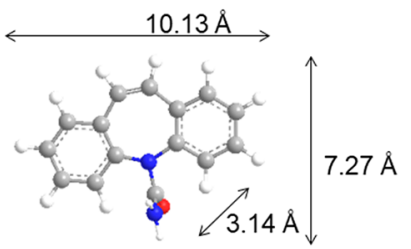

B

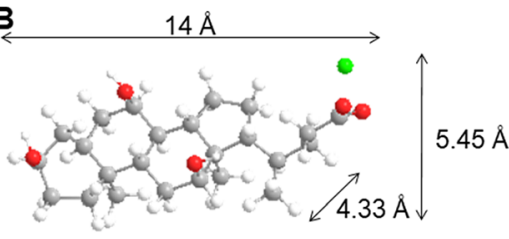

C

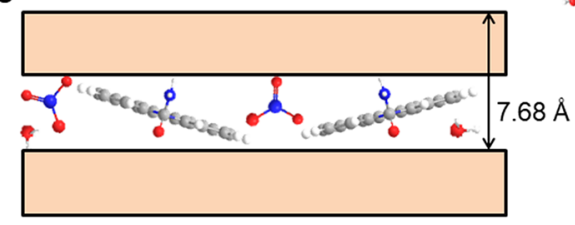

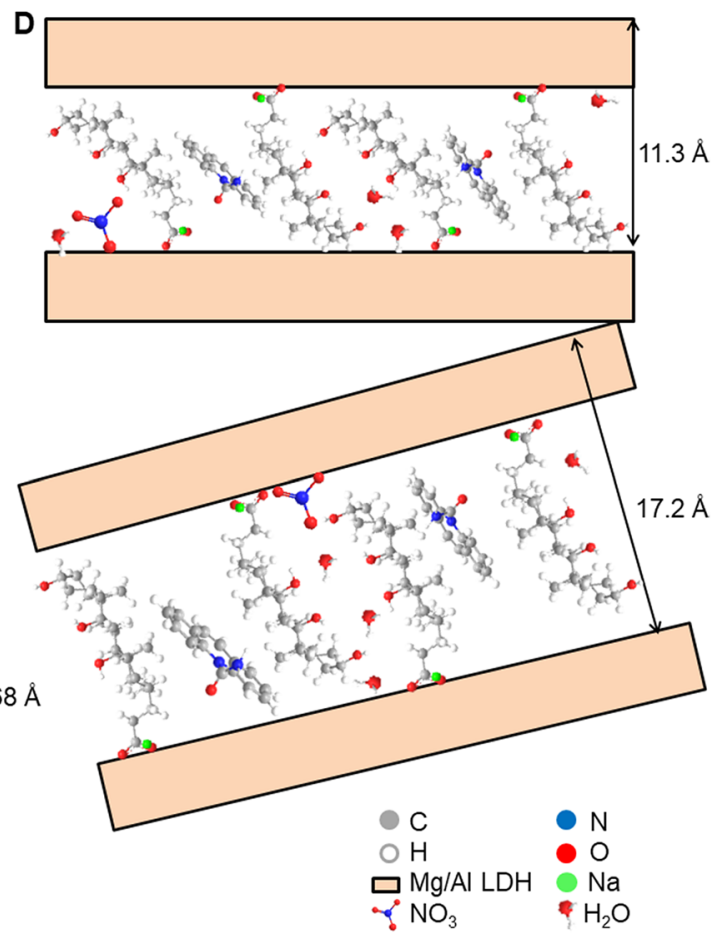

Figure 2. (a) CBZ dimensions calculated with Chem3D. (b) SC dimensions calculated with Chem $3 \mathrm{D}$. (c) Probable CBZ orientation in LDH-CBZ. (d) Probable CBZ and SC orientation in LDH-CBZ-SC60(IE).

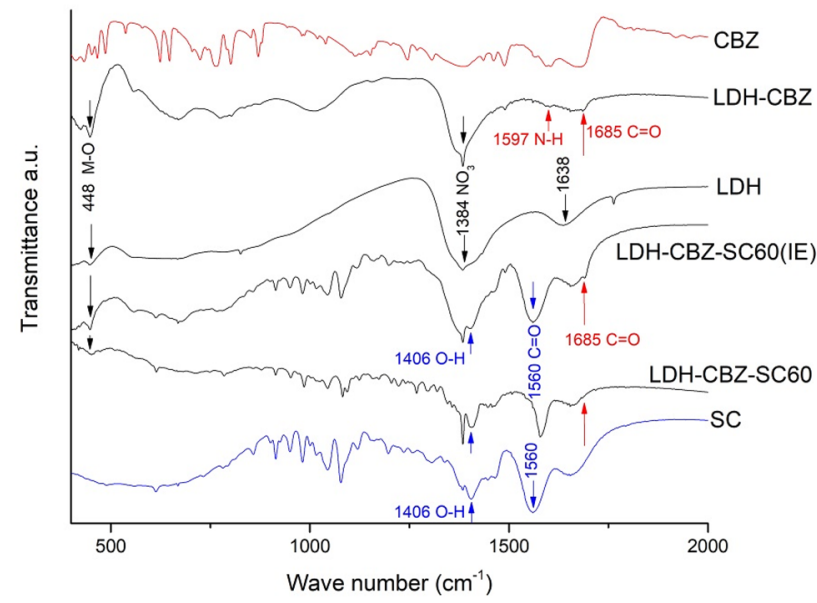

Figure 3. FTIR spectra of CBZ, SC, LDH and CBZ-LDH composites.

were measured with Chem3D 18.0 (Perkin Elmer) and are shown in Fig. 2a; Fig. 2c shows the way that CBZ might be accommodated into the $\mathrm{LDH}$, taking into account that no superficial drug appeared in the diffractogram.

In the samples containing SC, two peaks were observed, corresponding to basal spacings $\left(\mathrm{d}_{003}\right)$ of $11.5-9.9 \AA$ and 17.2-11.3 $\AA$ for LDH-CBZ-SC60 and LDH-CBZ-SC60(IE), respectively (Fig. 1). On the other hand, LDHCBZ-SC60 and LDH-CBZ-SC60(IE) samples exhibited large and asymmetric $\left(\begin{array}{lll}0 & 1 & 1\end{array}\right)$ reflections, indicating stacking faults. The diffraction pattern of LDH-CBZ-SC60 sample also shows some peaks characteristic of pure CBZ (Fig. $1,2 \theta=13.1^{\circ}, 15.3^{\circ}, 18.8^{\circ}, 23.2^{\circ}, 24.7^{\circ}$, and $26.6^{\circ 42-44}$ ), which indicates that some drug remained at the surface of the LDH. Taking into account the size of SC molecules, measured with Chem3D and displayed in Fig. 2b, we propose a probable organization of $\mathrm{CBZ} / \mathrm{SC}$ in the $\mathrm{LDH}$ as inclined monolayers with $\mathrm{CBZ}$ molecules located near the hydrophobic face of SC (Fig. 2d).

The characteristic transmittance peaks of CBZ, at $1597 \mathrm{~cm}^{-1}\left(\mathrm{~N}-\mathrm{H}\right.$ deformation) and $1685 \mathrm{~cm}^{-1}(\mathrm{C}=\mathrm{O}$ stretching $)^{45}$, appear in the FTIR spectrum of LDH-CBZ (Fig. 3), indicating that CBZ molecules were loaded into LDH. Absorption at $1384 \mathrm{~cm}^{-1}$, present in all samples, can be assigned to the $v_{3}$ vibration of $\mathrm{NO}_{3}{ }^{-}$, which is also in the interlayers. The band at $1638 \mathrm{~cm}^{-1}$, due to the bending mode of water molecules, disappears in the LDH-CBZ 

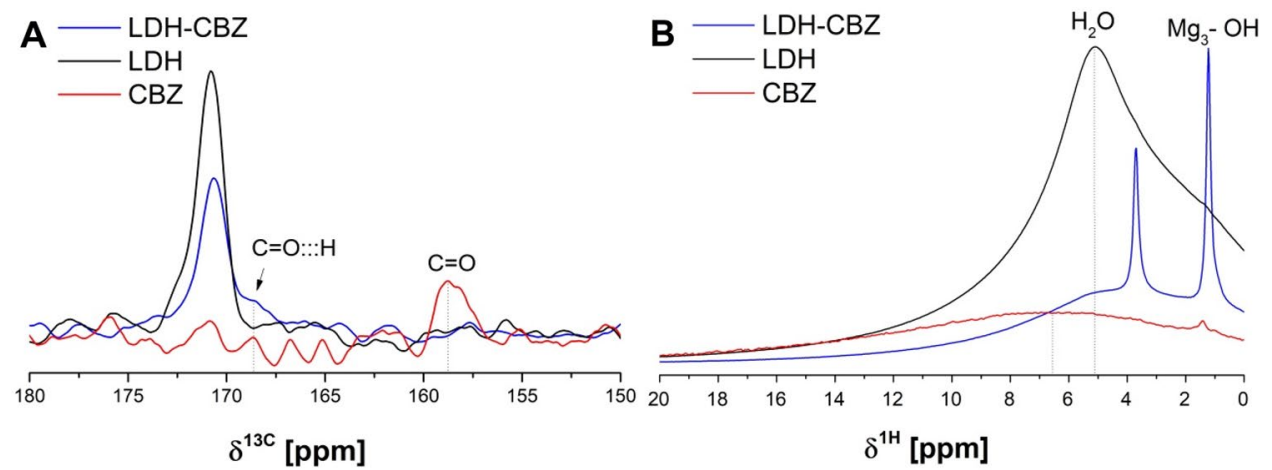

Figure 4. (a) ${ }^{13} \mathrm{C}$ and (b) ${ }^{1} \mathrm{H}$ solid state NMR spectra.
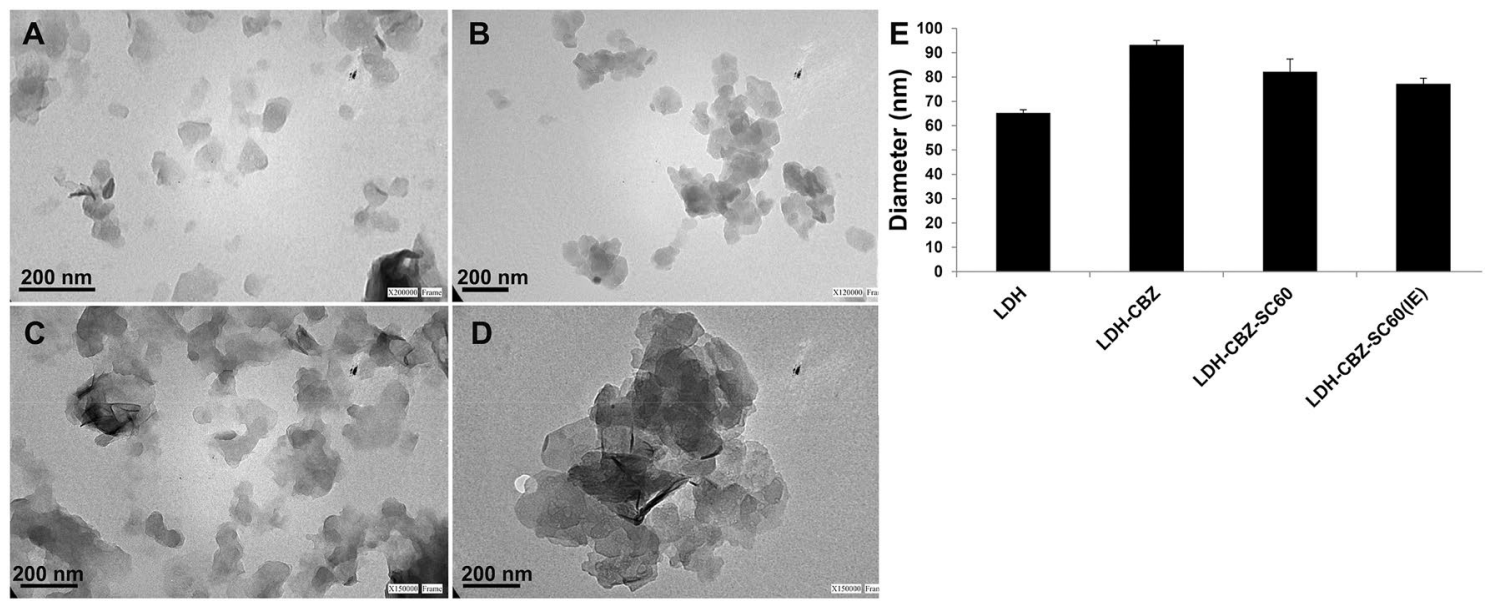

Figure 5. TEM images of (a) pristine LDH, (b) LDH-CBZ, (c) LDH-CBZ-SC60(IE), and (d) LDH-CBZ-SC60. (e) Diameter of LDH in different samples measured from TEM images.

spectra. The peak at $448 \mathrm{~cm}^{-1}$ is attributed to metal-O lattice vibrations. The spectra of the samples containing SC showed their characteristic peaks at $1406 \mathrm{~cm}^{-1}\left(\mathrm{O}-\mathrm{H}\right.$ vibrations) and $1685 \mathrm{~cm}^{-1}(\mathrm{C}=\mathrm{O} \text { stretching })^{46}$. These spectra were difficult to analyze since the surfactant bands are wide and strong and overlap the peaks of the CBZ (Fig. 3); however, the peak at $1685 \mathrm{~cm}^{-1}$ (C=O stretching) is detectable, which shows the presence of the drug in the composites. This absorption peak is weak for two reasons: the movement of CBZ in the composites is slower in comparison with the free drug, which produces the low IR absorption of the drug; and the concentration of the drug used in the synthesis is low ( $5 \%$ of the total components) ${ }^{46}$.

The molecular interactions through the $\mathrm{C}=\mathrm{O}$ group of $\mathrm{CBZ}$ and $\mathrm{LDH}$ were studied using ${ }^{13} \mathrm{C}$ NMR (Fig. $4 \mathrm{a}$ ). The noise/signal ratio was quite high in all the spectra; however, the $\mathrm{C}=\mathrm{O}$ chemical shift of the pure $\mathrm{CBZ}$ was around $158 \mathrm{ppm}$, in agreement with Ishizuka and Zhou ${ }^{43,47}$. The LDH-CBZ spectrum showed a peak shifted to higher values, at approximately $168 \mathrm{ppm}$, associated with hydrogen bonding ${ }^{48}$, which was broadened due to the interaction with the $\mathrm{OH}$ layer or water molecules of the interlayer. The resonance at $170 \mathrm{ppm}$ in the LDH and LDH-CBZ samples could be ascribed to interlayer carbonate species, but by FTIR spectroscopy it is not possible to detect the presence of carbonate; then it must be present only in a minor amount and it is probably adsorbed on the external surface of the solid as a result of carbonation by atmospheric $\mathrm{CO}_{2}{ }^{49}$.

In the ${ }^{1} \mathrm{H}$ NMR spectra of pure CBZ (Fig. 4b), the protons of the aromatic groups appeared at $6.5 \mathrm{ppm}^{47}$. The resonance peak at $5.1 \mathrm{ppm}$ in the $\mathrm{LDH}$ sample represents water occluded in the interlayers ${ }^{50-52}$; the intense water resonance reflects large water content in the intergallery of the empty LDH that significantly decreases with the incorporation of CBZ. The peaks at $1.2-1.3 \mathrm{ppm}$ correspond to $\mathrm{Mg}_{3} \mathrm{OH}$ interactions between the metals of the hydroxide sheets and the water of the interlayer, while the resonance at $3.7 \mathrm{ppm}$, which is visible only after the incorporation of $\mathrm{CBZ}$, corresponds to $\mathrm{MgAl}_{2}-\mathrm{OH}$ interactions. The higher intensity of the peak at $1.2 \mathrm{ppm}$ with respect to that at $3.7 \mathrm{ppm}$ is due to the metals ratio used in the synthesis ( $\mathrm{Mg}: \mathrm{Al}$ ratio 2:1). This trend also indicates that the $\mathrm{Al}$ and $\mathrm{Mg}$ cations must be ordered mainly in the metal hydroxide sheets.

TEM images (Fig. 5a-d) shows the laminar structure of LDH in all the samples, with the typical thin, platelike shape and dimensions below $100 \mathrm{~nm}$ (Fig. 5e). The addition of SC and CBZ did not change the dimension of the crystals although they tended to agglomerate them. In the samples with SC, the ion exchange method seems better than reconstruction, since aggregates are smaller (Fig. 5c,d respectively). 

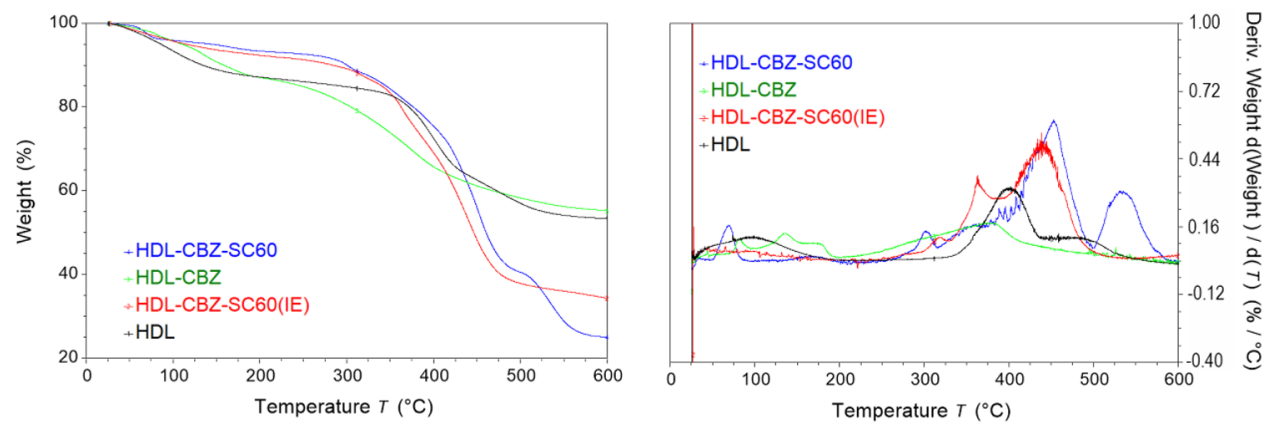

Figure 6. TG and DTG curves of composites.

\begin{tabular}{|l|l|l|}
\hline & CBZ loading (\%) & Encapsulation efficiency (EE) (\%) \\
\hline LDH-CBZ & $5.3 \pm 0.6$ & 75 \\
\hline LDH-CBZ-SC60 & $1.6 \pm 0.0$ & 75 \\
\hline LDH-CBZ-SC60(IE) & $1.8 \pm 0.2$ & 95 \\
\hline
\end{tabular}

Table 1. CBZ loading and encapsulation efficiency in the different composites.
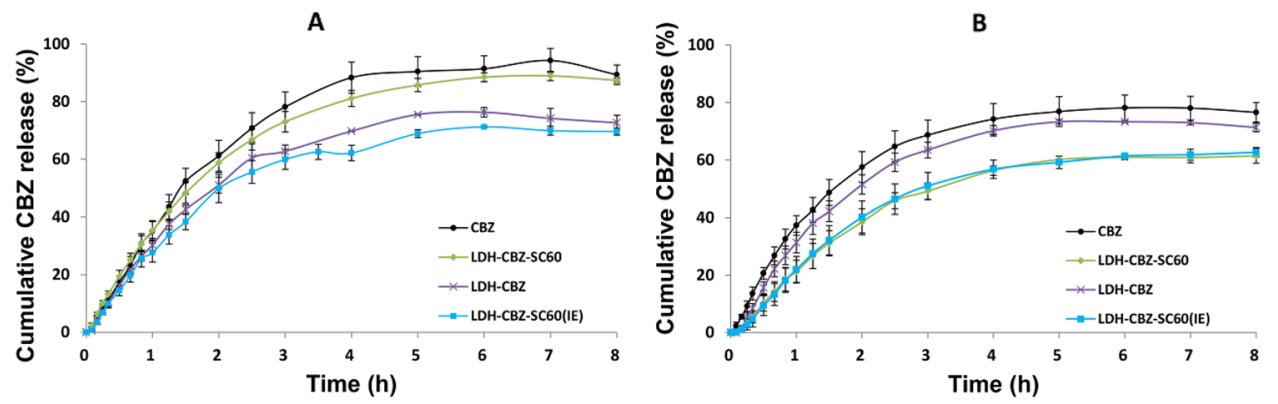

Figure 7. In vitro CBZ release profiles in (a) simulated body fluid (SBF), $\mathrm{pH} 7.4$ and (b) acetate buffer, $\mathrm{pH} 4.8$. $\mathrm{CBZ}$ solution in the respective mediums was used as reference (mean $\pm \mathrm{SD}, \mathrm{n}=3$ ).

Thermal behavior was determined by TG and DTG (Fig. 6). For LDH, the host solid, one weight loss stage can be observed at low temperatures. The maximum peak at $100^{\circ} \mathrm{C}$ is due to physically adsorbed water, and this stage ends at $200{ }^{\circ} \mathrm{C}$, which corresponds to the loss of interlayer water. The whole process represented a $13 \%$ weight lost, which indicates low hydration of the host solid. Finally, above $350{ }^{\circ} \mathrm{C}$, the dehydroxylation of the brucitelike sheets and the loss of interlayer ions indicate that the layer has disappeared. The TG curves of the samples containing SC depict a similar weight loss of around 70\%. In the LDH-CBZ sample, the total weight loss was only $45 \%$; this difference is due to the absence of SC. In the sample synthesized by reconstruction, DTG analyses revealed that the first thermal event, which occurred between 70 and $80^{\circ} \mathrm{C}$, corresponds to $\mathrm{CBZ}$ dehydration ${ }^{53,54}$; the transitions observed up to $170^{\circ} \mathrm{C}$ are associated with the removal of interlayer water. Finally, the last transition corresponds to SC decomposition ${ }^{55}$. In the LDH-CBZ-SC60(IE) sample it is not possible to observe a high loss of physically adsorbed water, due to the low moisture content present in the LDH host.

Table 1 shows the results of the CBZ loading into the LDH from the different synthesis methods. Encapsulation efficiency (EE) was high in all the samples; it was similar for LDH-CBZ and LDH-CBZ-SC60 (75\%), and its value increased to 95\% in LDH-CBZ0-SC60(IE).

The release profiles of CBZ, pure and from the different composites, are shown in Fig. 7. The patterns at $\mathrm{pH}$ 7.4 and 4.8 cannot be directly compared because CBZ behaves differently in the two mediums; the pure drug dissolves better and goes faster to the receptor medium at $\mathrm{pH} 7.4$ than at 4.8. The statistical analysis of these results was done by comparing the CBZ release profiles of the different systems with that one of the free drug. Table 2 shows the F1 and F2 factors, where F1 $<15$ and F2 $>50$ imply the release profiles are equals or similar.

The diffusion release mechanism of CBZ from LDH was verified by fitting for linearity between $-\ln \left(1-\mathrm{Q}_{\mathrm{t}} /\right.$ $\mathrm{Q}_{0}$ ) and $\mathrm{t}^{0.65}$, according to Bhaskar equations (Table 3). CBZ may have been released from $\mathrm{LDH}$ at $\mathrm{pH} 7.4$ by controlled diffusion, since the Bhaskar method showed linearity with an $\mathrm{R}^{2}$ of 0.9953 . The correlation coefficient 


\begin{tabular}{|l|r|l|l|l|l|l|}
\hline & \multicolumn{3}{|c|}{ SBF $(\mathbf{p H} 7.4)$} & \multicolumn{3}{l|}{ Acetate buffer $(\mathbf{p H}$ 4.8) } \\
\cline { 2 - 7 } & \multicolumn{1}{|c|}{ F1 } & F2 & Interpretation & F1 & F2 & Interpretation \\
\hline LDH-CBZ & 17.2 & 48.2 & Different curves & 10.7 & 64.9 & Similar curves \\
\hline LDH-CBZ-SC60 & 5.5 & 72.9 & Similar curves & 30.5 & 41.5 & Different curves \\
\hline LDH-CBZ-SC60(IE) & 22.9 & 42.3 & Different curves & 29.9 & 42.1 & Different curves \\
\hline
\end{tabular}

Table 2. Statistical analysis of CBZ release profiles. Comparisons were made for each system developed with respect to the free drug.

\begin{tabular}{|l|l|c|}
\hline Model & Equation & References \\
\hline Bhaskar & $-\ln \left(1-\mathrm{Q}_{\mathrm{t}} / \mathrm{Q}_{0}\right)=1.59\left(6 / \mathrm{d}_{\mathrm{p}}\right)^{1.3} \mathrm{D}^{0.65} \mathrm{t}^{0.65}$ & 56,57 \\
\hline Pseudo-first-order & $\ln \left(\mathrm{Q}_{\mathrm{e}}-\mathrm{Q}_{\mathrm{t}}\right)=\ln \mathrm{Q}_{\mathrm{e}}-\mathrm{K}_{1} \mathrm{t}$ & 58,59 \\
\hline Pseudo-second-order & $\mathrm{t} / \mathrm{Q}_{\mathrm{t}}=1 / \mathrm{K}_{2} \mathrm{Q}_{\mathrm{e}}{ }^{2}+\mathrm{t} / \mathrm{Q}_{\mathrm{e}}$ & 59,60 \\
\hline
\end{tabular}

Table 3. Equations for fitting the data of the CBZ release. $t$ time, $Q_{0}$ drug content at time $\mathrm{t}=0, Q_{t} \mathrm{drug}$ content at any time, $Q_{e}$ drug content at equilibrium, $d_{p}$ particle diameter, $D$ diffusivity.

\begin{tabular}{|c|c|c|c|c|c|c|}
\hline & & \multirow[b]{2}{*}{ Bhaskar } & \multirow[b]{2}{*}{ Parabolic diffusion } & \multicolumn{2}{|c|}{ Pseudo-first-order } & \multirow[b]{2}{*}{ Pseudo-second-order } \\
\hline & & & & & $\mathrm{K}_{1}\left(\min ^{-1}\right)$ & \\
\hline \multirow{2}{*}{ LDH-CBZ } & pH 7.4 & 0.9953 & 0.5993 & 0.9950 & 0.6404 & 0.9349 \\
\hline & $\mathrm{pH} 4.8$ & 0.9937 & 0.3500 & 0.9845 & 0.7525 & 0.9163 \\
\hline \multirow{2}{*}{ LDH-CBZ-SC60 } & pH 7.4 & 0.9896 & 0.7732 & 0.9852 & 0.6884 & 0.9815 \\
\hline & $\mathrm{pH} 4.8$ & 0.9940 & 0.1880 & 0.9795 & 0.6540 & 0.4043 \\
\hline \multirow{2}{*}{ LDH-CBZ-SC60(IE) } & $\mathrm{pH} 7.4$ & 0.9488 & 0.6236 & 0.9881 & 0.6364 & 0.9373 \\
\hline & pH 4.8 & 0.9876 & 0.0548 & 0.9720 & 0.7551 & 0.1614 \\
\hline
\end{tabular}

Table 4. Correlation coefficient $\left(\mathrm{R}^{2}\right)$ obtained by fitting the data of $\mathrm{CBZ}$ release into SBF ( $\left.\mathrm{pH} 7.4\right)$ and acetate buffer ( $\mathrm{pH} 4.8)$.

for the experiment at $\mathrm{pH} 4.8$ was also good, although a bit smaller: 0.9937 . CBZ can also be released from samples with SC by diffusion (Table 4).

The pseudo-first-order kinetic model was evaluated by fitting for linearity between $\ln \left(Q_{e}-Q_{t}\right)$ and $t$, according to the model equation, shown in Table 3. The rate constant $K_{1}$ was obtained from the slope of the linear plot. The pseudo-second-order kinetic model was evaluated by testing for linearity between $t / Q_{t}$ and $t$ (Table 3 ). Results are shown in Table 4 and Fig. 8; the pseudo-first-order model was the most satisfactory for describing the release kinetic processes of CBZ from the LDH-CBZ composite, with an $\mathrm{R}^{2}$ of 0.995 and a $\mathrm{K}_{1}$ of $0.64 \mathrm{~min}^{-1}$ at $\mathrm{pH} 7.4$ and an $\mathrm{R}^{2}$ of 0.985 and $\mathrm{K}_{1}$ of $0.75 \mathrm{~min}^{-1}$ at $\mathrm{pH}$ 4.8. The samples with SC also fitted better the pseudofirst-order kinetic model (Table 4$)\left(\mathrm{R}^{2}\right.$ between 0.969 and 0.988$)$ than the other one.

\section{Discussion}

CBZ is a neutral molecule that has shown activity against some cancer cell lines. The incorporation of the drug into LDH could avoid its side effects during blood circulation and allow its activity at the target sites. LDH are clays composed of cationic layers stabilized with anionic molecules that locate between them. SC, an anionic surfactant, was used to facilitate CBZ incorporation into the LDH interlayers, and the free drug was also incorporated into the $\mathrm{LDH}$ without SC for comparison purposes.

The synthesized LDH had a well-crystallized structure. The low value observed in the interlaminar distance may be due to the low hydration that the material presents. Other authors, who suggest that the nitrate anion accommodates itself in a parallel way to the brucite layer without widening due to the few water molecules that surround it, obtained similar data. Iyi et al. reported c values between 21.6 and $22.8 \AA$ A for nitrate anions ${ }^{61,62}$.

The structure and basal spacing of the LDH containing CBZ (without SC) were very similar to that of the LDH. The very small increase in the $\mathrm{d}_{003}$, can be due to the small size of the molecule (molecular size $=236 \mathrm{Da}$ ) ${ }^{63,64}$, which allows it to stay in the interlayer without changing its initial distance. The interlayer domains contain not only anions but also water and neutral molecules ${ }^{65}$, and the nonionic CBZ molecules perhaps could be stabilized in the gallery of $\mathrm{LDH}$ because of hydrogen bonds between $\mathrm{H}$ of $\mathrm{OH}$ (from brucite-type layers) and $\mathrm{O}$ or $\mathrm{N}$ of the $\mathrm{CBZ}$ molecules intercalated. These results agree with those of Dong et al. ${ }^{66}$, who reported that the incorporation of camptothecin, a molecule similar and slightly larger than CBZ, produced only a small increase in the interlayer 

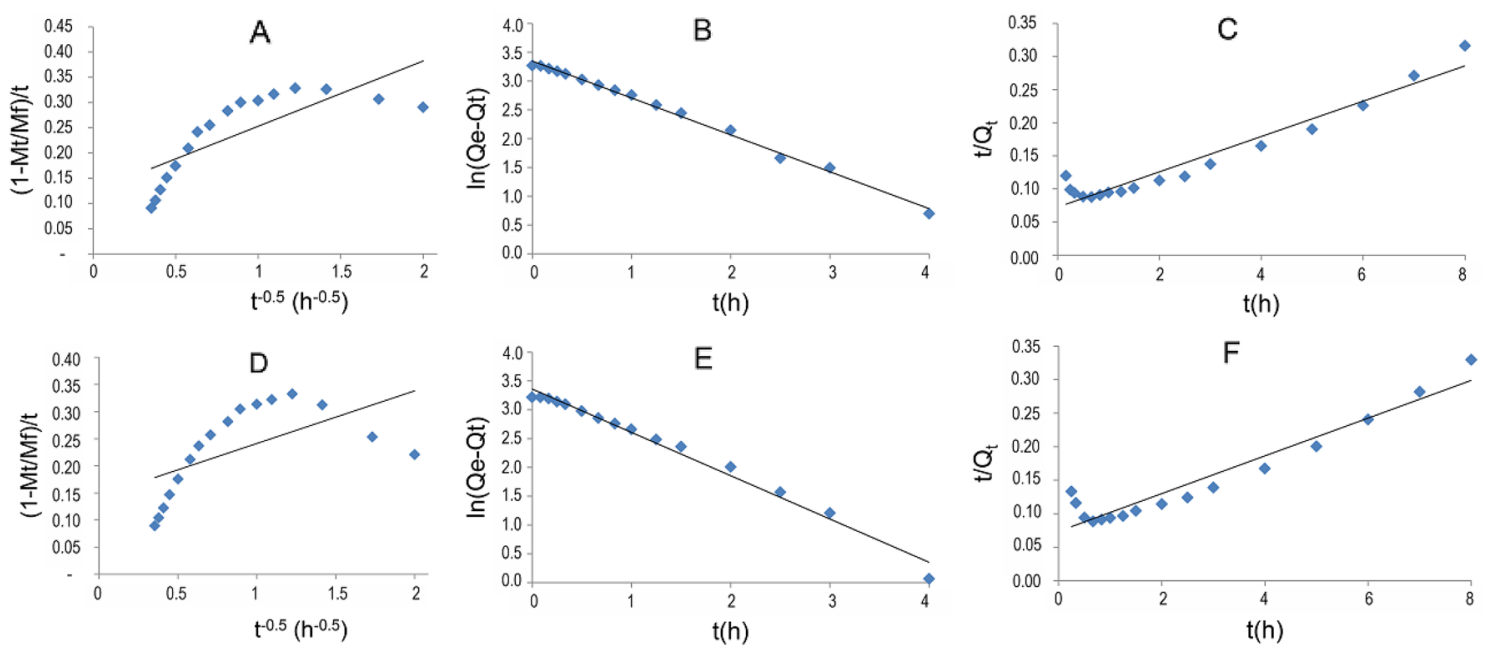

Figure 8. Fitting of the data of CBZ release from $\mathrm{LDH}-\mathrm{CBZ}$ composite to parabolic diffusion (a,d), pseudo-first $(\mathbf{b}, \mathbf{e})$ and pseudo-second (c,f) order kinetics for SBF, pH $7.4(\mathbf{a}-\mathbf{c})$ and acetate buffer, $\mathrm{pH} 4.8$ (d-f).

space. The authors propose that, in the LDH-CBZ system without SC, the molecules arrange as monolayers with the long axis parallel to the $\mathrm{LDH}$ layers.

Despite low percentage of drug used, it is possible to observe the peaks corresponding to CBZ in the FTIR and NMR spectra of the LDH-CBZ composites and infer its presence in the interlayers. The drug encapsulation efficiency was $75 \%$, and by X-ray diffraction superficial CBZ was not observed, unlike the LDH-CBZ-SC60 sample. In the solid-state ${ }^{1} \mathrm{H}$ NMR study, the concentration of interlayer water and hydroxyl groups results in large ${ }^{1} \mathrm{H}$ homonuclear dipolar couplings, which broadens the resonances and prevents the identification of chemically distinct ${ }^{1} \mathrm{H}$ environments ${ }^{50}$; in the LDH spectrum, where a broad peak appears with a maximum at $5.1 \mathrm{ppm}$ (water molecules), that phenomenon occurred. The incorporation of CBZ replaces some water and allows the definition of the peaks at 3.7 and $1.2 \mathrm{ppm}$ corresponding to $\mathrm{MgAl}_{2}-\mathrm{OH}$ and $\mathrm{Mg}_{3}-\mathrm{OH}$ respectively; this is in accordance with the decrease in the peak at $5.1 \mathrm{ppm}$ in the LDH-CBZ sample and the elimination of the peak at $1638 \mathrm{~cm}^{-1}$ in the FTIR spectrum. The higher definition of the peaks in the LDH-CBZ sample with respect to the empty LDH is then due to the presence of CBZ molecules in the interlamellar space, which replaces the interaction between water and metal hydroxides. Moreover, the ${ }^{13} \mathrm{C}$ spectrum of LDH-CBZ sample shows the interaction between the $\mathrm{C}=\mathrm{O}$ group of $\mathrm{CBZ}$ and the $\mathrm{OH}$ groups of the $\mathrm{LDH}$ layers and the remaining water molecules of the interlayer.

In the samples containing SC, the intensity of XRD peaks decreased in comparison with the LDH-host, indicating some reductions in crystallinity following the intercalation of SC and CBZ. Two basal planes were observed, which indicates different orientations of the CBZ-SC molecules in the LDH. The interlaminar distance observed is less than the size calculated for the SC (between 10-11 ̊ and $14 \AA$ respectively). This value assumes a slightly sloped monolaminar arrangement for the SC-CBZ molecules. SC molecules intercalated in the LDH alone or joined to CBZ cannot be distinguished.

The presence of the surfactant provides the interlaminar zone with a hydrophobic environment conductive to host the nonionic CBZ. CBZ is a hydrophobic molecule that accommodates near the hydrophobic face of SC and interacts with the surfactant through this face; a slight interaction such as hydrogen bonds between the amino groups of CBZ and hydroxyls of SC would not be ruled out. The SC carboxylate group interacts with the brucite layer through electrostatic forces ${ }^{67}$. A similar behavior was observed in the solid obtained by ion exchange. Larger basal planes were obtained (17 ̊̊), suggesting that SC-CBZ molecules fit into a tilted monolayer arrangement.

According to literature, the decomposition of pure CBZ begins at $200^{\circ} \mathrm{C}^{53,54}$; in DTG diagrams the decomposition is not observed until $300^{\circ} \mathrm{C}$, which can be associated with the superficial CBZ observed in LDH-CBZ-SC60 by XRD. From $350^{\circ} \mathrm{C}$, the decomposition of the sheets begins; the dihydroxylation of the lamella, decomposition and combustion of the intercalated CBZ occur together. The thermal decomposition temperature of the $\mathrm{CBZ}$ was strongly affected by the host layer. These results confirmed the enhanced thermal stability of the drug.

The CBZ loading into the $\mathrm{LDH}$, i.e., the percentage of CBZ in the system, was higher in $\mathrm{LDH}-\mathrm{CBZ}$ than in the samples with SC because of the fewer components of the synthesis. The drug encapsulation efficiency was high $(75 \%)$ and the same result was obtained with the systems with and without SC when the reconstruction method was used; this indicates that it is not necessary to incorporate SC together with CBZ into the LDH. The encapsulation was higher (95\%) in the sample with SC synthesized by ion exchange, but this method of synthesis cannot be applied in the case of the uncharged free drug; the basic principle of this synthesis method is that anionic molecules exchange with the anions located in the interlayers during agitation; when there is no other anionic molecules around the $\mathrm{LDH}$, the anions remain in the interlayer stabilizing the cationic layers and neutral molecules are not able to enter into the LDH.

Assays of in vitro drug release were done in Franz Cells with simulated body fluid ( $\mathrm{pH}$ 7.4) and acetate buffer $(\mathrm{pH} 4.8)$ in order to simulate and analyze the protective role of the nanosystem developed in the blood and the drug release inside the tumor cells respectively. Compared with the free drug behavior in the Franz Cells, LDH$\mathrm{CBZ}$ was the only system able to transport the drug at the $\mathrm{pH}$ value of the blood ( $\mathrm{pH} 7.4$ ) and release it at the 
$\mathrm{pH}$ value of the cell cytoplasm ( $\mathrm{pH} 4.8$ ). This was corroborated with the F1 and F2 factors, which statistically indicated that the release patterns of CBZ and LDH-CBZ were different at $\mathrm{pH} 7.4$ and similar at $\mathrm{pH}$ 4.8. The good three-dimensional structure obtained, observed by XRD, was able to control the drug diffusion in the matrix at $\mathrm{pH} 7.4$, and at acid $\mathrm{pH}$ it was destroyed, releasing CBZ in the medium. In the case of LDH-CBZ-SC60, the presence of $\mathrm{CBZ}$ at the surface of the $\mathrm{LDH}$ can explain the fast release of the drug at $\mathrm{pH} 7.4$. A controlled release of CBZ was obtained with the system synthesized by anion exchange (LDH-CBZ-SC60(IE)) at $\mathrm{pH} 7.4$ due to the predominant electrostatic interaction between the anionic SC and the brucite layer; however, the drug was not released at $\mathrm{pH} 4.8$, same that the system obtained with the reconstruction method. The presence of SC could stabilize the system, so the LDH dissolve more slowly at acidic $\mathrm{pH}$, and the hydrophobic face of SC attracts the CBZ molecules more than the aqueous medium present in the receptor compartment of Franz Cells. This behavior results in less release of CBZ. The release mechanism of CBZ from LDH, studied by Bhaskar method, seems to be a controlled diffusion in all the samples. At acidic $\mathrm{pH}$, diffusion is also the principal process for CBZ release, and LDH dissolve but slowly. CBZ can also be released from samples with SC by diffusion, although, as described above, not efficiently.

The kinetics of drug release from LDH composites is usually described with pseudo-first and pseudo-secondorder equations, or by parabolic diffusion ${ }^{13,66,68}$. The pseudo-first-order model was the most satisfactory in our systems. $\mathrm{K}_{1}$ values confirmed the faster release of $\mathrm{CBZ}$ at acidic than at neutral $\mathrm{pH}$ in $\mathrm{LDH}-\mathrm{CBZ}$ samples. In the samples with $\mathrm{SC}, \mathrm{K}_{1}$ values also confirmed the results discussed previously with CBZ release patterns. We also fitted the data with Ritger and Peppas, modified Freundlich, K-K and Higuchi models; however, their correlation coefficients were not sufficiently good.

\section{Conclusion}

Results suggest that not only ionic bonds are involved in the structure of LDH but other types of interactions also take place, such as hydrogen bonds. This is why these systems are suitable not only for loading anionic molecules but are also promising carriers of drugs with different charges, especially for the numerous neutral anticancer ones. $\mathrm{CBZ}$ molecules could incorporate into the $\mathrm{LDH}$ when the reconstruction method was used, without the need of surfactant. This system presented an enhanced thermal stability for CBZ and a good drug loading with acceptable encapsulation efficiency. Compared to the free drug behavior, it was also able to transport CBZ with high stability at $\mathrm{pH}$ of 7.4, and to release it rapidly at $\mathrm{pH} 4.8$, making it available inside the cell to exert its therapeutic effect. Thus this composite system may be a promising drug carrier for systemic administration of drugs targeted to intracellular sites, such as anticancer ones.

\section{Materials and methods}

Materials. Carbamazepine (USP grade, Parafarm) was provided by Saporiti, Argentina. Sodium cholate and $\mathrm{Al}\left(\mathrm{NO}_{3}\right)_{2} \cdot 9 \mathrm{H}_{2} \mathrm{O}(98 \%)$ were purchase from Sigma Aldrich, St. Louis, USA. $\mathrm{Mg}\left(\mathrm{NO}_{3}\right)_{2} \cdot 6 \mathrm{H}_{2} \mathrm{O}(98 \%)$ and $\mathrm{NaOH}$ (97\%) were supplied by Biopack and ethanol (absolute grade) by Sintorgan ${ }^{\circ}$.

Synthesis of composites. $\mathrm{LDH}$ were prepared by co-precipitation from $\mathrm{Mg}$ and $\mathrm{Al}$ nitrates. Two aqueous solutions of $\mathrm{Mg}\left(\mathrm{NO}_{3}\right)_{2} \cdot 6 \mathrm{H}_{2} \mathrm{O}(0.6 \mathrm{M})$ and $\mathrm{Al}\left(\mathrm{NO}_{3}\right)_{2} \cdot 9 \mathrm{H}_{2} \mathrm{O}(0.3 \mathrm{M})$ were prepared in $25 \mathrm{~mL}$ of decarbonated water, with a ratio of $\mathrm{M}^{2+} / \mathrm{M}^{3+}=2$. The solutions were added to $20 \mathrm{~mL}$ of decarbonated water at a rate of $1 \mathrm{~mL} /$ min, under permanent magnetic stirring. The coprecipitation was carried out at $70{ }^{\circ} \mathrm{C}$ under nitrogen atmosphere, to avoid the incorporation of $\mathrm{CO}_{2}$. The $\mathrm{pH}$ was maintained at $10.0 \pm 0.2$ by adding $\mathrm{NaOH} 2 \mathrm{M}$. The resulting suspension was stirred for $48 \mathrm{~h}$ under nitrogen atmosphere. The product was centrifuged and washed with decarbonated water until $\mathrm{pH} 7$, and finally dried at room temperature. For the reconstruction method, LDH were calcined at $450{ }^{\circ} \mathrm{C}$ for $9 \mathrm{~h}$ and stored at $120^{\circ} \mathrm{C}$.

The LDH-CBZ sample was prepared by the reconstruction method. CBZ (1 mg) was dissolved in ethanol $(1 \mathrm{~mL}) ; 16 \mathrm{mg}$ of calcined $\mathrm{LDH}$ and $18 \mathrm{~mL}$ of decarbonated water were added to the solution, and the mixture was stirred for $48 \mathrm{~h}$ at $40^{\circ} \mathrm{C}$, in a nitrogen atmosphere. The solvents were finally evaporated in a rotary evaporator at $60^{\circ} \mathrm{C}$, and the resultant powder was recovered.

For LDH-CBZ-SC samples, CBZ (1 mg) was dissolved in ethanol (1 mL); SC (60 mg) and decarbonated water $(8 \mathrm{~mL})$ were added to the solution and the mixture was stirred for $10 \mathrm{~min}$ under a nitrogen atmosphere in order to allow ethanol evaporation. The amount of water was related to the amount of SC, in order to maintain the critical micelle concentration. Then, $16 \mathrm{mg}$ of calcined LDH and $1 \mathrm{~mL}$ of water were added to the suspension, and the mixture was stirred for $48 \mathrm{~h}$ at $40^{\circ} \mathrm{C}$, in a nitrogen atmosphere. The solvents were finally evaporated in a rotary evaporator at $60^{\circ} \mathrm{C}$, and the resultant powder was recovered. Samples were called LDH-CBZ-SC60.

For comparison, LDH-CBZ-SC60(IE) was prepared by ion exchange method. The process was the same as that previously described, but LHD was incorporated in the original slurry $(1 \mathrm{~mL})$ instead of calcined.

Characterization. Powder X-ray diffraction (XRD) patterns were collected on a X'Pert Pro-PANalytical diffractometer using $\mathrm{Cu}$ Ka radiation $(\lambda=1.54 \AA)$ at a scan rate of $3^{\circ} / \mathrm{min}$ in $2 \theta$ and step size $0.02^{\circ}$ in a scan range between $2^{\circ}$ and $15^{\circ}$ and at a step time of $4.25 \mathrm{~s}$ and step size $0.026^{\circ}$ in $2 \theta$, continuous, in a scan range between $4^{\circ}$ and $70^{\circ}$.

Fourier transform infrared (FTIR) spectra were recorded on a Nicolet iS10 spectrometer at room temperature. The samples were pressed into a disc at 4 tons with $\mathrm{KBr}$. The spectrum of each sample was recorded by accumulating 48 scans at 2 and $4 \mathrm{~cm}^{-1}$ resolution, between 400 and $4000 \mathrm{~cm}^{-1}$.

High-resolution ${ }^{13} \mathrm{C}$ and ${ }^{1} \mathrm{H}$ solid-state spectra for all the samples were recorded using a CP-MAS pulse sequence (cross polarization and magic angle spinning) with proton decoupling during acquisition. All the solid-state NMR experiments were performed at room temperature in a 7 T Bruker Avance II-300 spectrometer 
equipped with a 4-mm MAS probe. The operating frequency for protons and carbons was 300.13 and $75.46 \mathrm{MHz}$, respectively. Glycine was used as an external reference for the ${ }^{13} \mathrm{C}$ spectra and to set the Hartmann-Hahn matching condition in the cross-polarization experiments. Adamantane was used as an external reference for the ${ }^{1} \mathrm{H}$ spectra. The recycling time was $7 \mathrm{~s}$ for CBZ, $3.5 \mathrm{~s}$ for LDH-CBZ, and $3 \mathrm{~s}$ for LDH sample. Contact time during $\mathrm{CP}$ was $2 \mathrm{~ms}$. The spinning rate for all the samples was $10 \mathrm{kHz}$.

Transmission electron microscopy (TEM) was performed in a JEOL JEM EXII 1200 microscope, operated at $80 \mathrm{kV} ; 0.5 \mathrm{mg}$ of sample was dispersed in $4 \mathrm{~mL}$ of deionized water and sonicated for $30 \mathrm{~min}$. A copper carbon grid was deposited on a small drop of the dispersion for $30 \mathrm{~s}$ and then allowed to dry. From TEM images, the diameter of each LDH was determined in two perpendicular directions using Fiji ImageJ software. In at least 4 images of each sample, all the well visible LDH were measured.

Thermogravimetric analysis (TG) was performed by means of an automatic thermal analyzer (TA Instrument, Discovery series). Thermal analyses were conducted at a scanning rate of $10{ }^{\circ} \mathrm{C} / \mathrm{min}$ from 25 to $600{ }^{\circ} \mathrm{C}$. The first derivative of TG (DTG) was determined with TRIOS TA Instrument software.

Carbamazepine encapsulation efficiency. The loading amount of CBZ in the LDH was determined with a Jasco V-650 UV-Visible spectrophotometer. A known amount of the system was placed in a $5 \mathrm{~mL}$ volumetric flask and $2.5 \mathrm{~mL}$ of $\mathrm{HCl} 1 \mathrm{M}$ solution was added to dissolve the inorganic layers. Ethanol was added to complete the final volume. The concentration of CBZ in the solution was determined at $284 \mathrm{~nm}$ using a calibration curve of $\mathrm{CBZ}$ in $\mathrm{HCl}$ :ethanol 1:1 v:v. The final value was an average of three independent samples. The CBZ loading was obtained according to the concentration of $\mathrm{CBZ}$ in the solution and the weight of the composite sample (Eq. 1).

$$
\text { Drug loading }(\%)=\frac{\text { amount of drug } \times 100}{\text { composite weight }}
$$

In addition, the drug encapsulation efficiency (EE) was calculated with Eq. $(2)^{69,70}$, where actual loading refers to the loading amount of CBZ obtained from the experimental process.

$$
E E(\%)=\frac{\text { actual loading } \times 100}{\text { theoretical loading }}
$$

In vitro carbamazepine release. The release of CBZ from LDH into simulated body fluid (SBF, $\mathrm{pH}$ 7.4, prepared as described by Cuello et al. ${ }^{71}$ ) and acetate buffer ( $\mathrm{pH} 4.8$ ) was achieved in vertical Franz cells under sink conditions (10\% saturation). Each sample (equivalent to $40 \mu \mathrm{g}$ of CBZ) was dispersed in $1 \mathrm{~mL}$ of the medium solution and added to the donor compartment. The receptor was filled with $9 \mathrm{~mL}$ of medium solution and maintained at $37{ }^{\circ} \mathrm{C}$ under agitation. Cellulose membrane of $14 \mathrm{kDa}$ (Sigma-Aldrich, USA) was used to separate both compartments. Then, $1 \mathrm{~mL}$ of sample was taken from the receptor medium at different times and replaced by fresh medium. The accumulated amount of CBZ released was measured in the UV-Visible spectrophotometer (Agilent Technologies Cary $60 \mathrm{UV}^{-V i s}{ }^{\oplus}$ ) at $284 \mathrm{~nm}$. Calibration curves in the respective mediums were used for $\mathrm{CBZ}$ concentration measurements.

From CBZ release patterns, molecule diffusion control was studied with the Bhaskar method ${ }^{56,57}$.

Release kinetics were studied with pseudo-first ${ }^{58,59}$ and pseudo-second-order ${ }^{59,60}$ kinetic models, and with parabolic diffusion, Ritger and Peppas, modified Freundlich, K-K and Higuchi models.

Statistical analysis. The difference factor (F1) and similarity factor (F2) were used to compare CBZ release profiles, according to Moore and Flanner ${ }^{72,73}$. The difference factor is a measurement of the relative error between the two curves (Eq. 3).

$$
F 1=\frac{\sum_{t=1}^{n}|R t-T t|}{\sum_{t=1}^{n} R t} \times 100
$$

where $\mathrm{n}$ is the number of time points, $\mathrm{Rt}$ is the release value of the reference (pure CBZ) at the time $\mathrm{t}$, and $\mathrm{Tt}$ is the release value of the test at time $t$.

The F2 is a measurement of the similarity in the percent release between the curves (Eq. 4).

$$
F 2=50 \times \log \left(\left[1+(1 / n) \sum_{t=1}^{n}(R t-T t)^{2}\right]^{-0.5} \times 100\right)
$$

For curves to be considered similar, F1 value should be close to 0 (up to 15) and F2 value should be close to 100 (greater than 50). 


\section{Data availability}

No datasets were generated or analyzed during the current study.

Received: 19 November 2020; Accepted: 5 October 2021

Published online: 18 October 2021

\section{References}

1. World Health Organization. Cancer. https://www.who.int/news-room/fact-sheets/detail/cancer\#: :text=Cancer is a leading cause,lung (2.21 million cases)\%3B. (2021).

2. Jin, K.-T. et al. Recent trends in nanocarrier-based targeted chemotherapy: Selective delivery of anticancer drugs for effective lung, colon, cervical, and breast cancer treatment. J. Nanomater. 2020, 9184284 (2020).

3. Hurria, A. et al. Predicting chemotherapy toxicity in older adults with cancer: a prospective multicenter study. J. Clin. Oncol. 29, 3457-3465 (2011).

4. Nicolas, J., Mura, S., Brambilla, D., Mackiewicz, N. \& Couvreur, P. Design, functionalization strategies and biomedical applications of targeted biodegradable/biocompatible polymer-based nanocarriers for drug delivery. Chem. Soc. Rev. 42, 1147-1235 (2013).

5. Hanafi-Bojd, M. Y. et al. Surface functionalized mesoporous silica nanoparticles as an effective carrier for epirubicin delivery to cancer cells. Eur. J. Pharm. Biopharm. 89, 248-258 (2015).

6. Lu, J., Liong, M., Zink, J. I. \& Tamanoi, F. Mesoporous silica nanoparticles as a delivery system for hydrophobic anticancer drugs. Small 3, 1341-1346 (2007).

7. Naz, S. et al. Advances in therapeutic implications of inorganic drug delivery nano-platforms for cancer. Int. J. Mol. Sci. 20, 965 (2019).

8. Ameena Shirin, V. K., Sankar, R., Johnson, A. P., Gangadharappa, H. V. \& Pramod, K. Advanced drug delivery applications of layered double hydroxide. J. Control. Release 330, 398-426 (2021).

9. Mallakpour, S., Hatami, M. \& Hussain, C. M. Recent innovations in functionalized layered double hydroxides: Fabrication, characterization, and industrial applications. Adv. Colloid Interface Sci. 283, 102216 (2020).

10. Laipan, M. et al. Layered intercalation compounds: Mechanisms, new methodologies, and advanced applications. Prog. Mater. Sci. 109, 100631 (2020).

11. Ebadi, M. et al. Drug delivery system based on magnetic iron oxide nanoparticles coated with (polyvinyl alcohol-zinc/aluminiumlayered double hydroxide-sorafenib). Alexandria Eng. J. 60, 733-747 (2021).

12. Barahuie, F., Hussein, M. Z., Gani, S. A., Fakurazi, S. \& Zainal, Z. Synthesis of protocatechuic acid-zinc/aluminium-layered double hydroxide nanocomposite as an anticancer nanodelivery system. J. Solid State Chem. Fr. 221, 21-31 (2015).

13. Hasan, S. et al. Controlled-release formulation of antihistamine based on cetirizine zinc-layered hydroxide nanocomposites and its effect on histamine release from basophilic leukemia (RBL-2H3) cells. Int. J. Nanomedicine 7, 3351-3363 (2012).

14. Mishra, G., Dash, B. \& Pandey, S. Layered double hydroxides: A brief review from fundamentals to application as evolving biomaterials. Appl. Clay Sci. 153, 172-186 (2018).

15. Senapati, S. et al. Layered double hydroxides as effective carrier for anticancer drugs and tailoring of release rate through interlayer anions. J. Control. Release 224, 186-198 (2016).

16. San Román, M. S., Holgado, M. J., Salinas, B. \& Rives, V. Characterisation of diclofenac, ketoprofen or chloramphenicol succinate encapsulated in layered double hydroxides with the hydrotalcite-type structure. Appl. Clay Sci. 55, 158-163 (2012).

17. Barik, S., Khandual, A., Behera, L., Badamali, S. K. \& Luximon, A. Nano-Mg-Al-layered double hydroxide application to cotton for enhancing mechanical, UV protection and flame retardancy at low cytotoxicity level. Cellulose 24, 1107-1120 (2017).

18. Jin, W., Lee, D., Jeon, Y. \& Park, D.-H. Biocompatible hydrotalcite nanohybrids for medical functions. Minerals 10, 172 (2020).

19. Yan, L., Gonca, S., Zhu, G., Zhang, W. \& Chen, X. Layered double hydroxide nanostructures and nanocomposites for biomedical applications. J. Mater. Chem. B 7, 5583-5601 (2019).

20. Kim, T.-H. et al. Anticancer drug-incorporated layered double hydroxide nanohybrids and their enhanced anticancer therapeutic efficacy in combination cancer treatment. Biomed Res. Int. 2014, 193401 (2014).

21. Kim, H.-J., Jeung, D.-G. \& Oh, J.-M. Boosting the anticancer activity of doxorubicin with a layered double hydroxide nanocarrier. Appl. Clay Sci. 203, 106000 (2021).

22. Mei, X. et al. Layered double hydroxide monolayers for controlled loading and targeted delivery of anticancer drugs. Nano Res. 11, 195-205 (2018).

23. Bhattacharjee, A., Rahaman, S. H., Saha, S., Chakraborty, M. \& Chakraborty, J. Determination of half maximal inhibitory concentration of CaAl layered double hydroxide on cancer cells and its role in the apoptotic pathway. Appl. Clay Sci. 168, 31-35 (2019).

24. Meng, Q. et al. Carbamazepine promotes Her-2 protein degradation in breast cancer cells by modulating HDAC6 activity and acetylation of Hsp90. Mol. Cell. Biochem. 348, 165-171 (2011).

25. Meng, Q.-W. et al. Inhibitory effect of carbamazepine on proliferation of estrogen-dependent breast cancer cells. Ai Zheng $\mathbf{2 5}$, 967-973 (2006).

26. Akbarzadeh, L., Moini Zanjani, T. \& Sabetkasaei, M. Comparison of anticancer effects of carbamazepine and valproic acid. Iran. Red Crescent Med. J. 18, e37230-e37230 (2016).

27. Ficarra, S. et al. Antiepileptic carbamazepine drug treatment induces alteration of membrane in red blood cells: Possible positive effects on metabolism and oxidative stress. Biochimie 95, 833-841 (2013).

28. Moradiya, H. G., Nokhodchi, A., Bradley, M. S. A., Farnish, R. \& Douroumis, D. Increased dissolution rates of carbamazepinegluconolactone binary blends processed by hot melt extrudion. Pharm. Dev. Technol. 21, 445-452 (2015).

29. Yamashita, H. \& Sun, C. C. Expedited tablet formulation development of a highly soluble carbamazepine cocrystal enabled by precipitation inhibition in diffusion layer. Pharm. Res. 36, 90 (2019).

30. Abou-Taleb, H. A., Fathalla, Z. \& Abdelkader, H. Comparative studies of the effects of novel excipients amino acids with cyclodextrins on enhancement of dissolution and oral bioavailability of the non-ionizable drug carbamazepine. Eur. J. Pharm. Sci. 155, 105562 (2020).

31. Li, M., Qiao, N. \& Wang, K. Influence of sodium lauryl sulfate and tween 80 on carbamazepine-nicotinamide cocrystal solubility and dissolution behaviour. Pharmaceutics 5, 508-524 (2013).

32. Suriyanon, N., Punyapalakul, P. \& Ngamcharussrivichai, C. Mechanistic study of diclofenac and carbamazepine adsorption on functionalized silica-based porous materials. Chem. Eng. J. 214, 208-218 (2013).

33. Wei, H. et al. Regenerable granular carbon nanotubes/alumina hybrid adsorbents for diclofenac sodium and carbamazepine removal from aqueous solution. Water Res. 47, 4139-4147 (2013).

34. Rajendran, K. \& Sen, S. Adsorptive removal of carbamazepine using biosynthesized hematite nanoparticles. Environ. Nanotechnol. Monit. Manag. 9, 122-127 (2018).

35. Park, D. H., Cho, J., Kwon, O. J., Yun, C. O. \& Choy, J. H. Biodegradable inorganic nanovector: Passive versus active tumor targeting in siRNA transportation. Angew. Chem. Int. Ed. 55, 4582-4586 (2016).

36. Oh, J.-M., Choi, S.-J., Kim, S.-T. \& Choy, J.-H. Cellular uptake mechanism of an inorganic nanovehicle and its drug conjugates: Enhanced efficacy due to clathrin-mediated endocytosis. Bioconjug. Chem. 17, 1411-1417 (2006). 
37. Foroozandeh, P. \& Aziz, A. A. Insight into cellular uptake and intracellular trafficking of nanoparticles. Nanoscale Res. Lett. 13, 339 (2018).

38. Torres-Vanegas, J. D., Cruz, J. C. \& Reyes, L. H. Delivery systems for nucleic acids and proteins: Barriers, cell capture pathways and nanocarriers. Pharmaceutics 13, 428 (2021).

39. Saraf, A., Sharma, S. \& Sachar, S. Evaluation of surfactants as solubilizing medium for levofloxacin. J. Mol. Liq. 319, 114060 (2020).

40. Tyner, K. M., Schiffman, S. R. \& Giannelis, E. P. Nanobiohybrids as delivery vehicles for camptothecin. J. Control. Release 95, 501-514 (2004).

41. Cursino, A. C. T., da Silva Lisboa, F., dos Santos Pyrrho, A., de Sousa, V. P. \& Wypych, F. Layered double hydroxides intercalated with anionic surfactants/benzophenone as potential materials for sunscreens. J. Colloid Interface Sci. 397, 88-95 (2013).

42. Panchal, J. G., Patel, R. V. \& Menon, S. K. Preparation and physicochemical characterization of carbamazepine (CBMZ): Parasulfonated calix [n] arene inclusion complexes. J. Incl. Phenom. Macrocycl. Chem. 67, 201-208 (2010).

43. Zhou, F. et al. Structure determination and in vitro/vivo study on carbamazepine-naringenin (1:1) cocrystal. J. Drug Deliv. Sci. Technol. 54, 101244 (2019).

44. Pinto, M. A. L., Ambrozini, B., Ferreira, A. P. G. \& Cavalheiro, É. T. G. Thermoanalytical studies of carbamazepine: Hydration/ dehydration, thermal decomposition, and solid phase transitions. Braz. J. Pharm. Sci. 50, 877-884 (2014).

45. Hardikar, S., Bhosale, A., Vanave, S. \& Kamathe, B. Preparation and evaluation of co-crystals of carbamazepine with glucomannan. Int. J. Pharm. Pharm. Sci. 9, 318 (2017).

46. Li, F., Jin, L., Han, J., Wei, M. \& Li, C. Synthesis and controlled release properties of prednisone intercalated Mg-Al layered double hydroxide composite. Ind. Eng. Chem. Res. 48, 5590-5597 (2009).

47. Ishizuka, Y. et al. Effect of drug-polymer interactions through hypromellose acetate succinate substituents on the physical stability on solid dispersions studied by Fourier-transform infrared and solid-state nuclear magnetic resonance. Mol. Pharm. 16, 2785-2794 (2019).

48. Maruyoshi, K. et al. Identifying the intermolecular hydrogen-bonding supramolecular synthons in an indomethacin-nicotinamide cocrystal by solid-state NMR. Chem. Commun. 48, 10844-10846 (2012)

49. Del Arco, M. et al. Mg, Al layered double hydroxides with intercalated indomethacin: Synthesis, characterization, and pharmacological study. J. Pharm. Sci. 93, 1649-1658 (2004).

50. Sideris, P. J., Nielsen, U. G., Gan, Z. \& Grey, C. P. Mg/Al ordering in layered double hydroxides revealed by multinuclear NMR spectroscopy. Science 321, 113-117 (2008).

51. Jensen, N. D., Bjerring, M. \& Nielsen, U. G. A solid state NMR study of layered double hydroxides intercalated with para-amino salicylate, a tuberculosis drug. Solid State Nucl. Magn. Reson. 78, 9-15 (2016).

52. Vyalikh, A. et al. From layered double hydroxides to layered double hydroxide-based nanocomposites: A solid-state NMR study. J. Phys. Chem. C 113, 21308-21313 (2009).

53. Pinto, M. A. L. et al. Thermoanalytical studies of carbamazepine: Hydration/dehydration, thermal decomposition, and solid phase transitions. Braz. J. Pharm. Sci. 50, 877-884 (2014).

54. Oparin, R. D., Vaksler, Y. A., Krestyaninov, M. A., Idrissi, A. \& Kiselev, M. G. High temperature polymorphic conversion of carbamazepine in supercritical CO2: A way to obtain pure polymorph I. J. Mol. Liq. 323, 114630 (2021)

55. Ramalingam, P., Pusuluri, S. T., Periasamy, S., Veerabahu, R. \& Kulandaivel, J. Role of deoxy group on the high concentration of graphene in surfactant/water media. RSC Adv. 3, 2369-2378 (2013).

56. Bhaskar, R., Murthy, R. S. R., Miglani, B. D. \& Viswanathan, K. Novel method to evaluate diffusion controlled release of drug from resinate. Int. J. Pharm. 28, 59-66 (1986).

57. Pagano, C. et al. Folic acid-layered double hydroxides hybrids in skin formulations: Technological, photochemical and in vitro cytotoxicity on human keratinocytes and fibroblasts. Appl. Clay Sci. 168, 382-395 (2019).

58. Lagergren, S. Zur theorie der sogenannten adsorption geloster stoffe. Bih. till K. Sven. Vetenskapsakademiens Handl. 24, 1-39 (1898).

59. Choudhary, M., Kumar, R. \& Neogi, S. Activated biochar derived from Opuntia ficus-indica for the efficient adsorption of malachite green dye, $\mathrm{Cu}+2$ and $\mathrm{Ni}+2$ from water. J. Hazard. Mater. 392, 122441 (2020).

60. Ho, Y. S. \& McKay, G. Pseudo-second order model for sorption processes. Process Biochem. 34, 451-465 (1999).

61. Jobbágy, M. \& Iyi, N. Interplay of charge density and relative humidity on the structure of nitrate layered double hydroxides. J. Phys. Chem. C 114, 18153-18158 (2010).

62. Iyi, N., Fujii, K., Okamoto, K. \& Sasaki, T. Factors influencing the hydration of layered double hydroxides (LDHs) and the appearance of an intermediate second staging phase. Appl. Clay Sci. 35, 218-227 (2007).

63. Yu, A. S. L. et al. Dialysis and extracorporeal therapies. In Brenner and Rector's The Kidney (Elsevier, Amsterdam, 2015).

64. Klein, P. \& Tolbert, D. Intravenous carbamazepine: A new formulation of a familiar drug. Expert Rev. Neurother. 17, 851-860 (2017).

65. He, J. et al. Preparation of layered double hydroxides. Struct. Bond. 119, 89-119. https://doi.org/10.1007/430_006 (2006).

66. Dong, L., Yan, L., Hou, W.-G. \& Liu, S.-J. Synthesis and release behavior of composites of camptothecin and layered double hydroxide. J. Solid State Chem. 183, 1811-1816 (2010).

67. Wang, B., Zhang, H., Evans, D. G. \& Duan, X. Surface modification of layered double hydroxides and incorporation of hydrophobic organic compounds. Mater. Chem. Phys. 92, 190-196 (2005).

68. Shafigh, M., Hamidpour, M. \& Furrer, G. Zinc release from Zn-Mg-Fe(III)-LDH intercalated with nitrate, phosphate and carbonate: The effects of low molecular weight organic acids. Appl. Clay Sci. 170, 135-142 (2019).

69. El-Say, K. M. Maximizing the encapsulation efficiency and the bioavailability of controlled-release cetirizine microspheres using Draper-Lin small composite design. Drug Des. Devel. Ther. 10, 825-839 (2016).

70. Ambrogi, V. et al. Eudragit ${ }^{\star}$ and hydrotalcite-like anionic clay composite system for diclofenac colonic delivery. Microporous Mesoporous Mater. 115, 405-415 (2008).

71. Cuello, N. I. et al. Drug release profiles of modified MCM-41 with superparamagnetic behavior correlated with the employed synthesis method. Mater. Sci. Eng. C 78, 674-681 (2017).

72. Moore, J. W. \& Flanner, H. H. Mathematical comparison of dissolution profiles. Pharm. Technol. 20, 64-74 (1996).

73. Notario-Pérez, F. et al. Development of pH-sensitive vaginal films based on methacrylate copolymers for topical HIV-1 preexposure prophylaxis. Acta Biomater. 121, 316-327 (2021).

\section{Acknowledgements}

The authors would acknowledge the financial support from Consejo Nacional de Investigaciones Científicas y Técnicas (CONICET), Universidad Tecnológica Nacional (UTN) and Universidad Nacional de Córdoba (UNC). They would like to thank Norma Graciela Maggia and the Thermal Analysis Laboratory, from UNITEFA-CONICET-UNC.

\section{Author contributions}

M.F.P. and S.N.M. wrote the main manuscript, R.I.S. prepared Fig. 7. All authors reviewed the manuscript. 


\section{Competing interests}

The authors declare no competing interests.

\section{Additional information}

Correspondence and requests for materials should be addressed to S.N.M. or M.E.C.

Reprints and permissions information is available at www.nature.com/reprints.

Publisher's note Springer Nature remains neutral with regard to jurisdictional claims in published maps and institutional affiliations.

(c) (1) Open Access This article is licensed under a Creative Commons Attribution 4.0 International License, which permits use, sharing, adaptation, distribution and reproduction in any medium or format, as long as you give appropriate credit to the original author(s) and the source, provide a link to the Creative Commons licence, and indicate if changes were made. The images or other third party material in this article are included in the article's Creative Commons licence, unless indicated otherwise in a credit line to the material. If material is not included in the article's Creative Commons licence and your intended use is not permitted by statutory regulation or exceeds the permitted use, you will need to obtain permission directly from the copyright holder. To view a copy of this licence, visit http://creativecommons.org/licenses/by/4.0/.

(C) The Author(s) 2021 